\title{
Is Romeo dead? On the persistence of organisms
}

\author{
Rina Tzinman ${ }^{1}$
}

Received: 2 September 2016 / Accepted: 17 April 2017 / Published online: 4 May 2017

(C) Springer Science+Business Media Dordrecht 2017

\begin{abstract}
According to a prominent view of organism persistence ("vitalicism"), organisms cease to exist at death. According to a rival view ("somaticism"), organisms can continue to exist as dead organisms. Most of the arguments in favor of the latter view rely on linguistic and common sense intuitions. I propose a new argument for somaticism by appealing to two other sources that have thus far not figured in the debate: the concept of naturalness, and biological descriptions of organisms, in particular in ethology and ecology. I show that if we hone in on the relevant notion of naturalness, we can show that organisms can (and often do) continue to instantiate the natural property being an organism after death.
\end{abstract}

Keywords Organisms · Death $\cdot$ Persistence $\cdot$ Naturalness $\cdot$ Biology

\section{Introduction}

Romeo was a happy 50-year-old chimpanzee. One day, he peacefully died. Judith, his caretaker, thinks he is merely sleeping, so she quietly waits for him to wake up, expecting him to have a late breakfast. Meanwhile, Peter, the other caretaker at the animal sanctuary checks on Romeo and determines he died moments ago. He hurries to inform Judith that, sadly, Romeo just died. Judith, surprised by the news, says: "Oh no! I was waiting for him to wake up, thinking he was asleep, but all this time he was actually dead!" Peter, however, tells her that she's wrong, because after he took his last breath, Romeo ceased to exist altogether. He explains that since organisms cease to exist at death, Romeo simply isn't there anymore.

Rina Tzinman

r.tzinman@gmail.com

1 Department of Philosophy, Bilkent University, H 249, Bilkent, 06800 Ankara, Turkey 
The underlying question that divides the views regarding Romeo is when organisms cease to exist. The answers divide into two main camps: (i) Vitalicism: organisms cease to exist at death, because a necessary condition for an organism to exist is for it to be alive (Van Inwagen 1990, p. 92; Olson 1997, 16, 29, 135; and Hershenov 2005); (ii) Somaticism: organisms cease to exist at some point after death, for instance, when they are cremated or otherwise physically destroyed (Mackie 1999; Carter 1988, 1989, 1999; Feldman 1992, Ch. 6; 2000; Thomson 1997). ${ }^{1}$ According to somaticists, an organism doesn't have to stay alive to persist, but it does have to remain more or less intact. This is the view I will argue for in the rest of the paper. While Judith may be wrong that Romeo is asleep, she is not wrong to think that he is now a dead chimpanzee, which was once alive.

My purpose is not to specify the exact persistence conditions of organisms, but only to argue that whatever they are, they allow organisms to persist through death. Although I am not committed to any particular way of filling in the details of somaticism in terms of necessary and sufficient persistence conditions, I will sketch one way of providing them as I discuss objections to somaticism: the historic dependence account.

The question of organism persistence is important for a number of reasons. First, according to a popular view of personal identity, animalism, we are identical to human animals. Therefore, our persistence conditions just are the human animal's persistence conditions (Olson 1997, pp. 16-17; 2003; Snowdon 1990, 1991, 1995). If animalism is true, then to settle the vitalicism/somaticism debate is to settle when we cease to exist. Second, how we answer the question may also have implications for how we conceptualize some professional activities, and even for some ethical issues. For example, if there are no dead organisms, coroners don't really study human animals, but at best traces of objects somehow related to them. Moreover, if organisms cease to exist at death, then perhaps we needn't worry about organ procurement without ante-mortem consent. For in that case, even if we are identical to human animals (or are somehow intimately and uniquely related to them), we are not justified in worrying about what happens to the human animal after death, because that object (the dead human animal, or the dead body) will not exist—or so have some argued. ${ }^{2}$

As I said, I will defend somaticism: dead organisms exist and are identical to the living organisms they result from. Existing defenses of this view appeal to intuition, e.g. by analogy to artifacts, or by appealing to ordinary language use and our everyday practices (Carter 1984; Feldman 1992; Mackie 1999). Instead, I will develop a new argument for the position, which does not appeal to these intuitions. I will argue that being an organism is a natural property, instantiated by both living beings and things we would normally recognize as dead organisms. If the property is instantiated by

\footnotetext{
1 I borrow this terminology from Blatti (2014), who makes an analogous distinction between somatic and organic versions of animalism about personal identity (I take this distinction to be parasitic on the somaticism/vitalicism distinction). The words 'terminator' and 'anti-terminator' are also frequently used in the literature, but they are ambiguous between views about organisms, persons, and bodies (see Hershenov 2005). Hence my preference for 'vitalicism' and 'somaticism', which refer unambiguously to theses about organism identity.

2 According to some vitalicist animalists, consent is not needed for organ procurement, since the composite objects we call corpses do not exist, and there is no object of posthumous harms (Delaney and Hershenov 2009; Hershenov and Delaney 2010).
} 
both, then we should not deny the existence of dead organisms. And if they exist, the best explanation for their existence is that they used to be living organisms. In a nutshell, the argument will be as follows:

$P 1$ Being an organism is a natural property.

$P 2$ If things instantiate the natural property of being an organism after death, then the simplest explanation of this fact is that dead organisms exist and are identical to the living organisms that they result from.

P3 There are things that instantiate the natural property of being an organism after death.

Conclusion The simplest explanation of (P3) is that dead organisms exist and are identical to the living organisms that they result from.

If the vitalicist wants to resist this argument, she should either show why her explanation is at least as simple as the somaticist's, or else deny that there are things that instantiate the natural property of being an organism after death.

My argument will draw on two areas that do not normally figure in debates on organism persistence: the metaphysics and philosophy of science literature on natural properties, and work in biology (especially population ecology and ethology). In what follows, I will first lay out the debate in a little more detail in Sect. 2.1. In Sect. 2.2 I will identify the relevant notion of naturalness, and in Sect. $2.3 \mathrm{I}$ will present the argument in favor of somaticism. This argument is, in effect, a burden shifter: given the main upshot of the preceding discussion (living and dead organisms both instantiate the natural property of being an organism), our default hypothesis should be that there is a single category under which living and dead organisms both fall. In Sect. 3 I will address four objections, and will argue that none of them succeeds at overturning this default hypothesis. I will conclude that we have powerful reasons-reasons largely independent from brute intuition or ordinary language use- to be somaticists.

\section{In defense of somaticism}

\subsection{Animals and death: setting up the debate}

The somatic view consists of the following claims:

(1) The existence claim dead organisms (composite objects resulting from, though not necessarily identical to, living organisms) exist. ${ }^{3}$

(2) The identity claim dead organisms are identical to the living organisms they appear to result from.

Most vitalicists are "corpse eliminativists", to borrow a helpful expression from Olson (2013): they deny the existence of corpses, and thus both (1) and (2). However, one

\footnotetext{
3 My use of the words 'dead organism' shouldn't be understood as automatically implying that dead organisms were once alive. For example, 'dead organism' might function similarly to 'counterfeit money', which of course doesn't refer to a kind of money at all (Mackie 1999, p. 222). Thanks to an anonymous referee for forcing me to be clearer about my use.
} 
can accept the existence claim and deny the identity claim in two ways ${ }^{4}$ : one can say either that (i) when a living organism ceases to exist, a dead organism comes to instantaneously replace it and so a new object-a corpse-comes into existence, or that (ii) the organism that will be dead was colocated with the living organism all along, so there is no new object that comes into existence after death (Olson refers to these as "corpse creationism" and "corpse concurrentism", respectively). Since most vitalicists are corpse eliminativists, the paper will assume that the main opponents of somaticism deny both (1) and (2). In the present dialectical context this is a legitimate assumption, since it makes my task harder; if you are a corpse creationist or a corpse concurrentist, then you are already on board with (1) and only need to be persuaded of (2).

\subsection{Being an organism: a natural property}

The contemporary notion of naturalness has first been introduced by David Lewis in his influential "New Work for a Theory of Universals" (1983). Lewis distinguishes various distinct roles that the concept of naturalness can play. While I cannot give an exhaustive discussion of these roles, it's worth pointing out that they roughly divide into two groups, corresponding to two importantly different concepts of naturalness: perfect naturalness and the scientific conception of naturalness. As it will later become clear, the notion relevant to our concerns is the second one. However, the enfolding discussion will be much easier to follow if we first make this distinction explicit. Neither of the two notions is plausibly analyzed in terms of more basic concepts; all I can provide below is an informative (if incomplete) characterization in terms of their theoretical roles.

The concept of perfect naturalness is often invoked to characterize the properties that serve as a minimal supervenience base for the rest of reality. On this conception, the perfectly natural properties are the most fundamental ones in the sense that they serve as a "blueprint" for the rest of reality. One way to cash out this metaphor is to say that in a metaphysically perspicuous language, all and only the perfectly natural properties would be expressed by logically simple predicates. Perfectly natural properties are also arguably discovered by fundamental physics; for example, the property of being negatively charged has a reasonably good claim to be perfectly natural. Apart from carving nature at the joints and serving as a minimal supervenience base, natural properties are sometimes construed as intrinsic properties that are preserved between duplicates, and as properties that can be freely recombined. Lewis also thinks of natural properties as those that account for similarity among their instances and dissimilarity among their non-instances. ${ }^{5}$

\footnotetext{
4 One can also deny (1) by claiming that there is an object after the organism's death, which is not a corpse or a dead organism; this object may or may not be something that used to be an organism. I will ignore this view in what follows: the first version seems to share all disadvantages of my view without its main advantage, whereas the latter is not relevantly different from corpse creationism. (Thanks to an anonymous referee for raising this option.)

5 For important works on perfect naturalness (and its various theoretical roles) see Lewis (1983, 1984), Sider (1993 [especially Chs. 3, 5-6, 9], 2011 [especially Chs. 1-3, 6-7]) and Dorr and Hawthorne (2013).
} 
There is also a second, scientific conception of naturalness. To some extent, it overlaps with the perfect naturalness conception, since (for example) it's plausible that scientifically natural properties, too, make for similarity among their instances and dissimilarity among their non-instances. However, scientifically natural properties aren't necessarily fundamental, nor do they constitute a supervenience base for the rest of reality. Instead, Schaffer argues that scientifically natural properties carve out causal powers $\left(2004\right.$, p. 94). ${ }^{6}$ Such causally efficacious properties may include having a certain mass, being a water molecule, and even being a desire (for example, having a desire to turn off the switch causes my turning off of the switch-see Schaffer 2004, pp. 94-95). Similarly, the property of being a water molecule has causal powers, which belong to the macro-property of being a water molecule: individual hydrogen or oxygen atoms do not have the causal powers that water molecules have (Schaffer 2004, pp. 94-95). ${ }^{7}$ This conception of natural properties as carving out causal powers is related to their figuring in scientific laws: the laws "codify their particular powers" (Schaffer 2004, p. 95). Besides carving out causal powers, scientifically natural properties are often thought to be discoverable by empirical means, though not necessarily by fundamental physics only, and intrinsically eligible to serve as the referents of our predicates. Note that these properties are not necessarily fundamental. ${ }^{8}$ So there doesn't have to be a rivalry between natural properties as those that figure in scientific laws, and perfectly natural properties that constitute a minimal supervenience base. ${ }^{9}$

Most of the naturalness literature has been devoted to the study of perfectly natural properties. Schaffer mostly focuses on drawing the distinction between the scientific and the perfect naturalness conception, and showing that there are natural properties in the scientific sense, but little has been written on natural properties in the scientific sense per se. Even most of Schaffer's own examples are taken from physics, and these are clearly not the kind of properties that are relevant to the question of organism persistence. Our focus should instead be on special science laws, with the caveat that the difference between laws and useful generalizations in the special sciences is blurrier than in physics. ${ }^{10}$ To bypass this complication, I will focus on some of

\footnotetext{
${ }^{6}$ Carving out causal powers means, roughly, specifying the features on which causal powers hinge (Schaffer 2004, p. 92).

7 See Kim (1998, p. 108) for more on the micro-basing relation.

8 For the scientific notion of naturalness and its roles see Armstrong (1978), Lewis (1983), Clapp (2001), Schaffer (2004) and Williams (2007).

9 Schaffer (2004) thinks there is rivalry between the scientific and the perfect natural conception, but unfortunately I lack space to examine his arguments in this paper.

10 According to one position, biology does not contain laws in the strict sense, i.e. laws that are "universal in that it is supposed that they apply everywhere in space and time, and they can be expressed in perfectly general terms without making use of proper names or of tacit reference to proper names" (Smart 1959, p. 360). Similarly, Beatty (1995) argues that there are no biological laws, if these laws are taken to be non-accidental generalizations. However, according to another position there are, in fact, biological laws. For example, Sober (1997) and Elgin (2006) argue that there are non-accidental generalizations in biology. Mitchell $(1997,2000)$ takes a different approach by arguing that we should favor a new conception of laws of nature that does not require laws to be non-accidental generalizations. She argues for a pragmatic approach to laws that offers "a multi-dimensional conceptual framework [that] should replace the standard dichotomous law/accident distinction in order to display important differences in the kinds of causal structure found in nature and the corresponding scientific representations of those structures" (Mitchell 2000, p. 242). Of
} 
the core concepts in biology, and some biological descriptions, in a way that avoids assuming anything about biological laws or generalizations. The properties picked out by these concepts and generalizations are reasonably considered natural in the scientific sense, independently of how inclusively in the end we decide to use the word 'law'. Presumably, organism is one of these concepts, since the property of being an organism is a key notion in biology. ${ }^{11}$ If we look at scientific practice we can examine how the concept organism figures in scientific descriptions, whether the property of being an organism applies to non-living things, and which of the somaticist and the vitalicist notion is fitter to be the target of biological practice.

Now we have a reasonably good grasp of the sense in which the property of being an organism is natural: the relevant notion is clearly scientific naturalness, rather than perfect naturalness. Organism is a key concept in biology that figures in a variety of descriptions, generalizations, and perhaps even laws. However, this doesn't yet tell us whether organisms could continue to exist as corpses. To answer this question in the affirmative, we need to show that the property of being an organism that is used in biology is one that putative corpses also instantiate. ${ }^{12}$ To simplify discussion I'm going to introduce two concepts. Something is a somatic organism only if it belongs to a set that involves every possible living organism and at least one possible corpse (this means that if corpses are not even possible, then nothing instantiates the property of being a somatic organism). And something is a vitalic organism only if it is a member of the set of every possible living organism. ${ }^{13}$ If somaticism is correct, then being an organism just is being a somatic organism; if vitalicism is right, then being an organism just is being a vitalic organism. ${ }^{14}$

\subsection{In defense of somatic organisms}

The basic strategy will be to see if we find areas within biology that can be plausibly (i) interpreted as quantifying over both living and dead things, and (ii) taken to assign the property of being an organism to both. If we can, we have reason to endorse both the Existence Claim and the Identity Claim, which jointly entail somaticism. However, not any sub-discipline in biology will work for this purpose. For instance, although biology

Footnote 10 continued

course, in the scope of this paper I cannot tackle such questions. I am assuming, however, that the properties used in biology (whether biology gives us laws of nature or not) are natural in the scientific sense specified by Schaffer.

11 For a short review of competing views regarding whether or not biologists need the concept of an organism, and an argument that they do, see Pepper and Herron (2008).

12 I am using the expression 'putative corpse' to avoid presupposing that dead organisms exist. In what follows I will argue that they do, but the expression 'putative corpse' is meant to be neutral between somaticism and vitalicism. (I thank an anonymous referee for asking me to clarify this point).

13 I thank an anonymous referee for pressing me on the exact formulation.

14 I am not assuming any particular theory of properties, and when I speak of the property of being a somatic organism, I have in mind abundant properties in the sense of Lewis (1983), i.e. simply the meanings of our predicates. It's not controversial to assume that there is an abundant property of being a somatic organism. The interesting question is whether there is a sparse property corresponding to this predicate; the discussion to follow is intended to provide some reason to think that there is. 
is interested in the study of life and living organisms, some biological disciplines, e.g. anatomy, are neutral with respect to the life status of the individuals they study. Other related disciplines, like bioarcheology, forensics and paleontology, are emphatically not interested in living organisms. Therefore, in what follows I will focus mostly on population ecology (the study of ecosystems) and zoology (in particular ethology), two sub-disciplines that, at least on the face of it, study living as well as dead organisms. (Of course, many vitalicists will want to say that strictly speaking no subdiscipline of biology studies dead organisms, but at best particles arranged dead-organism-wise. If you are one of these vitalicists, please bear with me; I will address this concern later.)

Recall that we are focusing on two properties, being a somatic organism and being a vitalic organism, and are trying to figure out which one is a better candidate to be identified with being an organism simpliciter. My argument will be as follows. First, I will argue that the property of being a somatic organisms is fitter to play at least some theoretical roles in biology, which gives us prima facie reason to posit somatic organisms. For example, the best biological description of a certain parasitic ant fungus's life cycle makes reference to both living and dead ants. Second, I will consider cases in which the property of being a vitalic organism might seem fitter to play other theoretical roles. These cases face us with a choice: (i) posit both organisms with vitalic and organisms with somatic persistence conditions, (ii) posit only the former, or (iii) posit only the latter. I will ignore (i), since it's clearly the least parsimonious option (nor is it endorsed by either party to the debate). Instead, I will focus on (ii) and (iii) and will argue that while somaticists can easily accommodate the theoretical roles of organisms with vitalic persistence conditions, the most natural vitalicist strategy for filling in the roles normally assigned to dead organisms has to pay a heavy price in terms of theoretical simplicity. Therefore, we should only posit organisms with somatic persistence conditions.

I will focus on the life cycle of a fungal parasite that manipulates an ant, kills it, and then uses the ant's body for its own growth and reproduction (ants infected by the fungus are popularly known as "zombie ants"). Before I describe the case in more detail, however, I should explain why I chose to focus on this case. As I mentioned, some biological disciplines are mainly interested in post-death biological phenomena (e.g. bioarcheology, forensics), and one would think it would be easiest to focus on these branches of biology in order to show that dead organisms exist-for otherwise what could they be studying? However, such an approach would pose the following problem. One could argue that, since these disciplines are only interested in post-mortem occurrences, they do not study organisms, but only things causally related to what used to be organisms (e.g. particles arranged dead-organism-wise). If I focused on a case that only involved living animals, on the other hand, I would face a triviality or easiness problem: of course such cases demonstrate that living organisms instantiate the natural property of being an organism, but that is something that few if any would disagree with. Additionally, such cases would not tell us anything about whether organisms instantiate the property of being an organism after they die. By focusing on a case that seems to describe an organism as persisting through death, I can do two things: (i) avoid the triviality or easiness problem, and (ii) show that such descriptions would be unnecessarily complicated if they involved-as the vitalicist 
would have it - two kinds of things (living and dead organisms, or living organisms and particles arranged dead-organism-wise).

I should note that the claim that positing organisms with somatic rather than vitalic persistence conditions is simpler is not a claim about language; it's a claim about the world. If it's also simpler to talk about somatic organisms, then this is just an accident about us. We can easily imagine a linguistic community that has a primitive linguistic expression, 'schmorganism', which applies to living organisms as well as pluralities of particles arranged dead-organism wise. This community might find it easier to talk about "schmorganisms", but they would be wrong to conclude that there is a natural property of being a schmorganism. Accordingly, in arguing for somaticism on simplicity grounds I'm not just naively reading this conclusion off ordinary language. What I do assume is that our best science generally succeeds at picking out fairly natural properties. This assumption shouldn't be controversial: after all, it's built into the naturalness role that the natural properties prominently figure in scientific theories. Of course, the assumption is very much defeasible in individual cases; it might turn out that some predicate in our best science fails to refer to a natural property (think of 'jade' before the nineteenth century, when nephrite and jadeite were discovered to have different chemical compositions). But in these cases, we simply learn that neither our best science nor the natural properties are what we took them to be. That such cases are possible is a good thing. Somaticism is a thesis in applied metaphysics; unlike (say) linguistic ersatzism about possible worlds, it cannot be established on purely a priori grounds and should be open to empirical refutation.

This being said, we should be careful about how empirical evidence bears on the vitalicism/somaticism dispute. ${ }^{15}$ In scientific contexts, simplicity is often thought to be a good guide to theory choice on the basis that simpler theories fit the data better or lead to better predictions (see Sober 2015, especially Ch. 2; Forster and Sober 1994). According to these criteria, a simpler theory will not be empirically equivalent to a less simple theory. But as I said, the debate between somaticism and vitalicism is one in applied metaphysics, not in biology. So even if the theories are empirically equivalent in the narrow sense that the world would perceptually seem the same way to us whether vitalicism or somaticism were true, that still wouldn't mean that naturalness doesn't make some kind of an empirical difference to the question. ${ }^{16}$

Specifically, even if the theories are equivalent in this narrow sense, this does not mean that empirical evidence does not bear on the debate. Empirical evidence can still help us determine which properties confer causal powers, lend themselves to stronger generalizations, allow for simpler systematization, and so on. Empirical adequacy

\footnotetext{
15 I thank an anonymous referee for pointing out the need to clarify this issue.

16 Note that if the theories are not empirically equivalent even in the narrow sense, the vitalicist would be in trouble in any case. As the discussion to follow will clarify, vitalicists presuppose that they can find an empirically equivalent paraphrase of sentences that confer commitment to somatic organisms into sentences that don't. So, for the sake of the argument I will assume that neither somaticism nor vitalicism is simpler in any sense that would touch on the theories' empirical adequacy. In addition, it might in principle turn out that one of the two organism concepts is so gerrymandered as to not even be the meaning of a projectible predicate (e.g. not support counterfactual generalizations). While I grant that this could in principle turn out to be the case, I don't find it very likely in the case with vitalic and somatic organisms. (Thanks to an anonymous referee for helping me make my position clearer.).
} 
(in the narrow sense) could always be preserved by replacing natural properties with extensionally equivalent Boolean combinations of non-natural ones. (For instance, take a language in which the word 'schmorganism' is a possibly degenerate plural term that refers to either a living organism or some particles arranged dead-organismwise. Then, even if being a vitalic organism is a natural property, every occurrence of 'vitalic organism' could be replaced with 'schmorganism not identical to some particles arranged dead-organism-wise'.) Nonetheless, it's an empirical question which properties are fit to serve as primitives in a theory: two theories can be empirically equivalent in the narrow sense even if one of them uses predicates that carve closer to the joints (cf. Sider 2011, Ch. 1). ${ }^{17}$ It is in this sense that somaticism is a simpler theory than vitalicism-or so I shall argue below.

Back to the example! As I said, I will focus on a specific type of insect parasite that disables and then kills ants: the fungus Ophiocordyceps unilateralis sensu lato, first documented by Alfred Russell Wallace in $1859,{ }^{18}$ is a parasite that specializes on arboreal Camponotus leonardi ants (carpenter ants) (Andersen et al. 2009). ${ }^{19}$ The fungus infects ants, modifies their behavior, kills them and uses their dead bodies for further growth and reproduction. Specifically, the fungus causes the infected ant to leave its nest in the canopy, climb up the foliage and clamp onto the underside of a leaf (this is also known as the "death grip"), where the ant is killed by the parasite. ${ }^{20}$ This case is particularly interesting because the host's death is only the starting point "for a major part of parasite development" (Andersen et al. 2009, 428), and has also been described as a "developmental necessity" for the parasite (Hughes et al. 2011, 2 ). After the ant dies, the fungus fortifies the ant's body and produces a large stalk that prodrudes and grows from the back of the ant's head, which is followed by a release of spores from the fruiting ant body when the fungus is ready to reproduce (see Hughes et al. 2011; Pontoppidan et al. 2009).

Numerous studies have focused on this specific parasite-host relationship, examining the mechanisms that underlie parasite-induced manipulation of the hosts' behavior (De Bekker 2014), the behavioral effects that ant graveyards (a high-density aggregation of dead infected ants) have on foraging hosts (non-infected ants) (Pontoppidan et al. 2009), etc. All these studies appear to assume that the zombified ant is used by the parasite both before and after death, and that the ant's corpse exists after death.

\footnotetext{
17 On the widespread view that theories are sets of sentences, when comparing rival theories for simplicity, we are strictly speaking comparing linguistic items. But linguistic items can be compared not only with respect to linguistic simplicity, but also with respect to the simplicity of the phenomena they posit. It is this very much worldly notion of simplicity that I have in mind, even if the means through which I investigate it may well be linguistic.

18 See Hughes et al. (2011).

19 See also Mongkolsamrit et al.: "The fungus Ophiocordyceps unilateralis sensu lato (Ascomycota, Hypocreales, Ophiocordycipitaceae, anamorph Hirsutella formicarum) is an entomopathogenic fungus specific to Formicine ants (Formicinae, Formicidae) found in tropical rainforests." (2012, p. 217).

20 Note that the death location is not random: "dead infected ants were located 25.20 $\pm 2.46 \mathrm{SE} \mathrm{cm}$ above the ground, where the humidity and temperature were optimal for fungal growth, and on the north-northwest side of the plant biting onto a vein of the leaf. Parasites in the dead ants relocated from this 'manipulative zone' did not grow, confirming the adaptive value of the behavioral change". (Andersen and Hughes 2012, 163).
} 
Importantly, these studies also discuss the role of dead ants for parasite reproduction, and also some behavioral trends that are related to the effect dead ants have on living ants. So the dead ants are not simply taken to be a means to infer something about the once living ants (as one could argue is the case in, e.g., forensics). Furthermore, the dead ant's ecological role isn't easily assigned to any combination of ant-parts, or portions of mere ant tissue.

For instance, some of the cases I will present (see (D) and (E) involve a relation between an aggregation of dead ants and a variable. Assigning the role of the dead ants to a combination of ant parts or portions of ant tissues would be extremely difficult not only because it would be more cumbersome to count the tissue or ant parts, but because it would also be difficult to individuate those parts without referring to their owners. For instance, it's difficult to see how talk of a high-density aggregation of dead ants (number of dead ants per $\mathrm{m}^{2}$ ) could be paraphrased into talk of ant tissue. To begin with, how can we even count dead ant tissue, given that 'ant tissue' is a mass noun? Moreover, if we moved to mass terms rather than count nouns (e.g. 'portion of ant tissue'), we would lose a valuable piece of explanatory information concerning how the infection of some particular number of ants leads to the appearance of some particular number (indeed, the same number) of dead ants. The move from 'dead ant' to 'ant tissue' threatens to obfuscate this strict connection. Eliminativists could of course talk about how the amount of ant issue is related to the number of particular living ants that were infected. But unfortunately, there is no strict correlation between these two variables. Ants come in different sizes and are composed by differently sized portions of ant tissue, so each individual living ant will explain the appearance of some different amount of ant tissue. Thus, an important piece explanatory connection (roughly: "One dead ant per infected ant!") is lost in translation.

The following examples are all taken from studies that examine this parasite-host relation. They all mention both living and dead ants, since that is required to describe the parasite's life cycle. ${ }^{21}$ For the present purposes, we can focus on the parts that refer to the dead ants:

(A) Dead ant anatomy "The period of infection may be as short as 3-6 days and once the infected ant is dead the fungus produces a large stalk, growing from the back of the ant's head" (Pontoppidan et al. 2009, p. 2 my emphasis)

(B) Dead ant anatomy "The fungus can apparently go through several cycles... For instance, if a disturbance occurs and destroys the stromata or they degenerate on

\footnotetext{
21 Note that while I am focusing on a particular biological case, this is shorthand for a number of cases, because $\mathrm{O}$. unilateralis represents a species complex, containing several species, which attack several species of carpenter ants (Evans et al. 2011, p. 598) and have a pantropical forest distribution on formicine hosts (p. 601). As hypothesized by Evans et al. (2011), "there may be hundreds of species within the complex parasitizing formicine ants worldwide" (p. 598). So the phenomenon is not widespread in terms of being common beyond this species complex, but it is widespread (and therefore not very unique) because the phenomenon doesn't just characterize one species. Moreover, the genus cordyceps (a genus of fungi) includes over four hundred species, which are parasitic mainly on insects (not only ants). In addition, the case has implications about diversity. Evans et al. (2011) suggest that if their study was repeated on a global scale, it could reveal "that there are tens if not hundreds of species still to be delimited within the complex" (p. 601). This has significance both for addressing the question of "to what degree does this diversity scale up?" and for reconsidering "the oft repeated mantra that arthropods are the true "kings of the jungle', especially when species diversity is the parameter of interest” (Evans et al. 2011, p. 601).
} 
the ants' bodies, a new stroma can grow from the same ants' bodies until the ants completely disappear". (Mongkolsamrit et al. 2012, p. 218 my emphasis)

(C) The role of the dead ant's body in the life cycle of the fungus "We therefore hypothesized that $O$. unilateralis has evolved a syndrome of stepwise sequential traits to achieve its reproductive success, beginning with manipulation of the host into dying in an optimal location for fungal development, followed by colonization and exploitation of the dead host body in a way that secures the resources in competition with the abundant decomposers found in tropical forests. We tested this by determining the narrow manipulation zone of dead infected ants and characterizing parasite development in this zone with experimentally relocated hosts as controls" (Andersen et al. 2009, p. 425 my emphasis)

(D) Correlation between a variable and number of dead ants "O. unilateralis/ $\mathrm{H}$. formicarum occurrence on ants has a seasonal pattern with peaks in both the rainy and dry seasons. The amount of rainfall correlates with the number of new dead ants when a time lag of 1 month is included, whereas no correlation is found when no time lag is considered. This result may reflect the fact that the fungus needs a certain time to develop and to infect the ants..." (Mongkolsamrit et al. 2012, p. 223 my emphasis)

(E) Correlation between some variables and the number of dead ant aggregations and impact of dead ant graveyard on living ant foraging behavior" We established that high density aggregations exist (up to 26 dead ants $/ \mathrm{m}^{2}$ ), which we coined graveyards. We further established that graveyards are patchily distributed in a landscape with no or very few O. unilateralis-killed ants. At some, but not all, spatial scales of analysis the density of dead ants correlated with temperature, humidity and vegetation cover. Remarkably, having found 2243 dead ants inside graveyards we only found 2 live ants of the principal host, ant Camponotus leonardi, suggesting that foraging host ants actively avoid graveyards." (Pontoppidan et al. 2009, p. 1 my emphasis)

In all of these examples, (putative) dead ants have a role in certain biological explanations. $^{22}$ Their shared assumption is that the dead ant is the same ant that was infected and manipulated by the fungus. We can see this clearly in (A) ("once the infected ant is dead the fungus produces a large stalk") and (C): to achieve its reproductive success, the fungus begins with manipulating the host into dying in an optimal location and then exploits the host's dead body. The (simplest) assumption seems to be that the fungus is manipulating one object throughout." According to somaticists, these examples all quantify over dead organisms that are identical to the organisms that the fungus manipulated as part of its life cycle. So ants-alive or dead-form a natural category not because of their behavior, but because of their causal role in phenomena for which it is important that they are organisms with certain structural features, but not important that they are alive.

\footnotetext{
22 Note that in (A) the fungus is said to grow from the back of the ant's head. This description is significant because it does not involve the qualification "dead" to describe the ant, although at the point the ant is no longer alive. So biologists seem to assume that the living infected ants are identical to the resulting objects after death. In addition to (A), the description in (C) also shows that scientists take phrases like "the dead ant's body", "the infected dead ant" and "the ant" to refer to the same object.
} 
At this point, the vitalicist might argue that we could simply paraphrase talk of dead organisms into talk of particles arranged dead-organism-wise (for such an attempt see Van Inwagen 1990, pp. 108-114). But if we carefully examine the two strategies, we can argue that the somatic approach has the upper hand in terms of simplicity: the somaticist's descriptions are quite simple in comparison to the miscellaneous descriptions of the vitalicist.

In order to formulate these descriptions, the vitalicist would have to first quantify over living organisms and then quantify over particles arranged dead-organism-wise. By contrast, the somatic view needn't introduce quantification over a different kind of thing in order to formulate scientific descriptions. Since dead organisms exist, it is strictly speaking true that, e.g., "the fungus produces a large stalk, growing from the back of the ant's head" (Pontoppidan et al. 2009, p. 2). So even if vitalicism can describe such data, the somatic view seems to have the upper hand in terms of simplicity. In the particular case of the ant and the fungus the somaticist can give a more perspicuous description of the parasite's life cycle, since the death of the ant does not mark a particularly important turning point in its progress. It does not matter exactly when the ant dies; the ant plays a very similar role in the parasite's development 5 min before and $5 \mathrm{~min}$ after its death. So, there's something very unnatural about formulating two different generalizations in biology, as if there was a big difference from the fungus's point of view. (From a certain point onwards, e.g. after the fungus manipulates the ant into moving under a leaf and biting into it, the ant's structural features are more important for the fungus than whether it is dead or alive. This claim highlights a feature of my preferred version of the somatic view, which I will later explore in more detail: it gives the notion of structure a more prominent role in understanding organisms and it gives life a less prominent role. One way in which structure might be more important in this case is that the stroma of the fungus always protrudes from back of the dead ant's head.)

The vitalicist may object in the following way. Suppose that there are some descriptions in biology that only quantify over living animals. The somatic view does not capture what is unique about such descriptions. For instance, studies of bird migration only care about living specimens that can actually migrate. So while somaticism better captures some bits of biology, vitalicism more precisely captures others. However, note that somaticists can easily introduce a restriction to the effect that generalizations about migration trends and behaviors concern living birds. Such restrictions don't affect these generalizations in any significant way, since they concern the very same entities according to the somaticist as according to the vitalicist (they just disagree over their persistence conditions, but that's an entirely different matter.) By contrast, when it comes to dead organism vitalicists must quantify over particles arranged dead-organism-wise, whereas somaticists may simply talk about organisms that are no longer alive. So while the somatic view can just make do with one kind of organism when describing biological phenomena, vitalicism must bifurcate the theoretical role originally assigned to organism. Somaticists therefore have a theoretical advantage over vitalicists: they can formulate their theories in terms of one general organism concept that all generalizations about organisms intuitively use and avoid the burden of explaining how generalizations about vitalic organisms are related to generalizations about corpses or particles arranged corpse-wise By contrast, the somatic restriction 
approach makes it perfectly transparent how the same somatic organisms can figure in generalizations intuitively about living organisms and generalizations intuitively about dead ones. $^{23}$

Note that my point isn't that it's impossible to paraphrase away quantification over dead organisms. The paraphrase strategy comes in only if you already have independent arguments against the existence of corpses. The paraphrase strategy can then be used to explain away apparent talk about corpses, but it cannot be used as an argument against somaticism (after all, talk of living organisms could also be paraphrased into talk of particles arranged organism-wise). The availability of the paraphrase strategy does not address the issue that law-like generalizations in biology are better phrased in terms of somatic organisms. So you cannot use the paraphrase to argue that organisms are necessarily alive. All it shows is that the view is coherent, but I am not denying that.

Apart from not being an argument against somaticism, the paraphrase strategy would also introduce extra complications. Such paraphrases would yield much less simple generalizations than those that only quantify over dead organisms. Take, for example, generalization (D) above: "The amount of rainfall correlates with the number of new dead ants when a time lag of 1 month is included". For any natural number n, we can paraphrase quantification over n number of composite objects into quantification over some $x$ s, some $y$ s, some $z \mathrm{~s}$ (etc.) such that the $x$ s don't overlap the $y$ s, the $x$ s don't overlap the $z \mathrm{~s}$, the $y \mathrm{~s}$ don't overlap the $z \mathrm{~s}$, and so on until we grouped all the particles into the desired number of non-overlapping pluralities. But it's much less clear how we can paraphrase correlational claims that don't appeal to any particular number of dead ants. It won't do, for example, to say for any non-overlapping xs, ys, and zs arranged dead-and-wise, if there were more rainfall there would be some non-overlapping $\mathrm{x}^{*} \mathrm{~s}$, $\mathrm{y}^{*} \mathrm{~s}, \mathrm{z}^{*} \mathrm{~s}$ and ws arranged dead-and-wise. This is both too weak in being specific to an increase from three dead ants to four, and too strong in interpreting a correlational claim as a specific claim about the exact numerical increase in dead ants.

Perhaps one could do a little better than this, in all likelihood by paraphrasing correlational claims into an unimaginably long nested disjunction of conditionals linking raises in temperature to particles arranged dead-ant-wise. But if this were possible, it would result in a far less simple and vastly less explanatory theory. This is not just a point about linguistic inconvenience or elegance of expression. Such disjunctions would also, on the whole, refer to less natural properties than a theory cast in terms of dead ants. To mention just one problem, the resulting theory would attribute too much significance to the individual arrangements figuring in the disjuncts, while failing to account for what's common to those arrangements.

\footnotetext{
23 One worry is that attributing roles to living and to dead organisms will end up being disjunctive, because there are things that only living or that only dead organisms can do. This may count against attributing a single role to the organism concept. However, it's not generally true that the concept has to be maximally nondisjunctive. For instance, there are things that only young organisms do and things that only mature organisms do. So we need to balance between having reasonably non-disjunctive theoretical roles and sufficiently unified biological laws or generalization. Sometimes we need to sacrifice some non-disjunctiveness to achieve some unity in the generalizations. Otherwise we would have different organism concepts for an organism's offspring and adult organisms. I believe I provided some reason to think that the unity achieved by subscribing to the somatic organism concept is worth it. (I thank an anonymous referee for pressing me on this issue).
} 
The line of thought I presented above is not meant to be a knock-down argument against the vitalicist, but more like a burden-shifter: our best relevant science, biology, appears to quantify over organisms that persist through death. It is possible to propose various paraphrases, but that by itself does not shift the burden back to the somaticist. My claim is not that there is no other way to formulate biological descriptions and generalizations, but that as they are formulated by practicing biologists they seem to favor somaticism, and vitalicist-friendly reformulations would be inferior for independent reasons. One can of course use paraphrase as a defensive move, but one cannot use it as a positive argument for vitalicism.

The argument presented here does not conclusively refute vitalicism. But it shows that science is on the side of the somaticist, although vitalicists often give the impression as if this was not the case (that the somaticist's position is scientifically naïve): our best science operates with the somaticist, rather than the vitalicist, organism concept. While this does not conclusively refute vitalicism, it shows that somaticism shouldn't be on the defense when it comes to scientific considerations. This improves the dialectical position of the somaticist.

To conclude, I have argued that according to the simplest interpretation of biological practice, being a (somatic) organism is a central notion of biology. Given the scientific conception of naturalness, this gives us some reason to think that being a somatic organism is a good candidate to be meant by 'is an organism', and a better candidate than being a vitalic organism is. Therefore, all organisms have somatic persistence conditions and can thus persist through death. This concludes my defense of somaticism.

\section{Objections and replies}

In what follows, I will address four objections to my defense of somaticism: the causal powers objection, the informativeness objection, the unprincipledness objection, and the disjunctiveness objection. The four objections proceed from what is arguably the weakest objection, to the strongest objection.

\subsection{The causal powers objection}

Earlier, I said that according the relevant conception of naturalness - the scientific conception - natural properties carve out causal powers. However, what kind of causal powers does the putative corpse possess? For example, when the fungus uses the infected carpenter ant before its death, it manipulates the ant into moving away from the ant colony and biting into a leaf. But in what sense does the dead ant have causal powers? Studies describe living ants actively avoiding high-density aggregations of dead ants (Pontoppidan et al. 2009), fungus developing in a way that attaches the ant more firmly to the leaf, preserves the cuticle as well as the its muscles for many weeks after its death (Andersen et al. 2009, pp. 431), etc. But, the vitalicist could argue, these post-mortem causal powers are properly attributed to the ant's parts and not to the ant itself. After all, it's these parts that play a role in the fungus's development and reproduction. 
The problem with this objection is that it trades on an ambiguity in the way the words 'doesn't have causal powers' have been used in the literature. In the first sense of 'doesn't have causal powers' it might be somewhat plausible that dead ants do not have causal powers. But that is not the sense that is generally taken to be relevant for determining which properties are natural according to the scientific notion of naturalness. In the second sense, the ants "not having causal powers" would be a good reason to think that being a dead organism is not a natural property. However, in this sense it is also false that the ant does not have causal powers. So, there is no plausible reading of "doesn't have causal powers" on which this argument succeeds—or so I will argue below. ${ }^{24}$

The claim that corpses don't have causal powers could come down to two things: (a) they don't have non-redundant causal powers; or (b) they don't have causal powers that are sufficiently unified. ${ }^{25}$ According to (a) the causal powers of organisms are reducible to those of their parts or constituents. On this interpretation, if organisms don't have causal powers then neither do rocks, rivers and mountains. Though I doubt that not having causal powers in this sense is a good reason to eliminate something from our ontology, it is beyond the scope of this paper to show this. ${ }^{26} \mathrm{I}$ am content to point out that corpses are natural objects in the same sense in which other inanimate objects in the natural sciences are.

According to (b), only properties with sufficiently unified causal powers are natural. The main idea behind a property carving out causal powers is that the sorts of things that instantiations of the property cause and the sorts of things that cause instantiations of the property are sufficiently similar. For example, the property of being an electron or being a chair clearly corresponds to causal powers that show very little similarity. By contrast, being a mountain, being a river or being a storm are bona fide candidates to be the objects of the special sciences, so they are bona fide bearers of unified causal powers. On this interpretation, it would indeed be a problem if being a somatic organism didn't have causal powers. Fortunately, the problem doesn't arise: we have seen that somatic organisms play important roles in special science generalizations and do have sufficiently unified causal powers. ${ }^{27}$

Let's take stock. In whatever sense dead organisms don't have causal powers, in that sense neither do macroscopic objects like tectonic plates, rocks or celestial bodies (since they derive their causal powers from their parts). Since it is pretty clear that these are all covered by the scientific notion of naturalness, they all have causal powers

\footnotetext{
${ }^{24}$ I thank an anonymous referee for raising the issue of different senses of (not) having causal powers and its relation to natural properties.

25 Of course, a third option is that they do not have causal powers at all. But this cannot be the appropriate sense of "not having causal powers" since material objects (unlike mathematical abstracta, for instance) can cause things.

${ }^{26}$ Merricks (2001) famously argues that no $x$ s compose an object unless that object has non-redundant causal powers. While his argument is intriguing, there are various ways in which they can be resisted. The literature on Merricks's overdetermination argument is vast; see Sider (2003), Yang (2013), Árnadóttir (2015), and many others.

27 If having causal powers means having non-redundant causal powers, then there would be little point in distinguishing natural properties in the scientific sense from natural properties in the perfectly natural sense.
} 
in the intended sense. Derivative or not, if the causal powers in question are unified enough, that's good enough for characterizing properties that are natural according to the scientific conception.

\subsection{The uninformativeness objection}

The vitalicist can argue that so far I have defended somaticism in a way that does not tell us anything informative about the following: (i) what counts as a part of a corpse (see Olson 2004, 2013), (ii) the conditions under which organisms persist after death.

Let's start with the first issue: can the somaticist provide an informative account of the mereological behavior of corpses? For example, suppose that there is an artificial heart implanted in a human animal. Is the heart part of the corpse, once the human animal dies? My answer to this question is short: although somaticism doesn't by itself immediately imply anything about when an organism has something as a part, neither does vitalicism. For example, Liao (2010) believes that animals can have artificial organs as parts, whereas Olson (1997, pp. 141-142) doesn't. So, somaticism as such isn't any less informative than vitalicism with respect to questions of parthood. One might, of course, prefer a particular version of vitalicism that legislates about these questions, but there is nothing in vitalicism that settles the issue.

The question of persistence is trickier. In discussing this problem, it's worth putting aside corpse concurrentism and corpse creationism, since whatever uncertainties about organism persistence beset somaticism equally arise for these views in the form of puzzles about corpse persistence. Focus instead on corpse eliminativism. In order to fully capture descriptions that quantify over living and dead organisms, corpse eliminativists would have to specify conditions under which some particles arranged corpse-wise bear the right kind of spatiotemporal, causal (etc.) relations to the living organism they result from. If they cannot do so, then the respective paraphrases are unsatisfactory. But if they can give such conditions, then the somaticist can say that it's exactly those conditions under which a corpse persists and is identical to the living organism it results from. So, to the extent that corpse eliminativists can say something informative about when particles arranged corpse-wise display the right kind of continuity needed by the relevant biological generalizations, somaticists can also say something informative about the persistence conditions of somatic organisms.

One may object that the somaticist cannot simply piggyback on the vitalicist's account of persistence. ${ }^{28}$ Unlike the somaticist, the vitalicist's paraphrase isn't constrained by the formal properties of identity. So an adequate vitalicist paraphrase strategy may not yet furnish the somaticist with the means to provide an adequate criterion of organism persistence through time. However, there is a long standing practice of giving paraphrases that try to capture such diachronic identity claims. Of course, the vitalicist (or more generally, the eliminativist) does not have to say that the original English sentences are true, but she still needs to say something about the correctness (or assertability) conditions of cross-temporal identifications. More specifically, it is

\footnotetext{
28 Many thanks to an anonymous referee for pressing me on this point, and for helping me substantially improve the discussion here.
} 
widely accepted among eliminativists that an English sentence is correct just in case if the ontology of common sense (or the kind of ontology they deny) were true, it would be true (see Merricks 2001, Ch. 7). Since every sentence true by somaticist standards has to come out as at least correct or assertable by vitalicist standards, it is a mistake to think that the corpse eliminativist has a lot of extra leeway with his paraphrase strategy. Thus, if the eliminativist can give an appropriate paraphrase stategy, the somaticist can simply "steal" it: she can maintain that whichever sentences the eliminativist thinks are correct are in fact true. ${ }^{29}$

The eliminativist might argue that the paraphrases he uses to capture corpse persistence might result in sentences that the somaticist cannot (or at least should not) accept as true. For example, the vitalicist might use the controversial tool of "plurally plural" quantification (Uzquiano 2004). However, the somaticist can respond in the following way. When the vitalicist paraphrases the somaticist, he does not have to claim that the paraphrase is truth preserving. The somaticist can say the same thing: the conditions under which the somaticist's sentences about organism persistence are true are the conditions under which the vitalicist's sentences are (by somaticist standards) correct. For example, even if sentences employing plurally plural quantification are not true, they can still be correct; and so, the truth conditions of the somaticist's statements can be captured in terms of the correctness conditions of the vitalicist's.

But doesn't the vitalicist in turn have to specify these correctness conditions in terms of what would be true if somaticism were true, which-from the somaticist's point of view-is simply what is true? Either he has to or he doesn't have to. If he doesn't have to, the somaticist has thereby provided the adequate truth conditions for sentences about when somatic organisms persist. If he does have to, then for the paraphrase to be successful, we need to assume that the somaticist already provided such truth conditions (whatever they are). In short: the somaticist does not do a worse job at providing persistence conditions than the vitalicist does at paraphrasing the somaticist's sentences about cross-temporal identity. If the somaticist fails, the vitalicist fails; if the vitalicist succeeds, the somaticist succeeds as well.

The above defense of somaticism against the uninformativeness objection is, of course, a tu quoque. In order to show how the somaticist can provide further details about persistence, I will now focus on a particular version of somaticism, the historicdependence account. To be clear, somaticists can also favor a different account of persistence. The following discussion should simply serve to make clear that the somaticist can fill in the details about persistence conditions.

According to the historic-dependence view, when an organism is alive, it stays in existence because it is alive, whereas once an organism dies it persists through time because it was once alive (and specifically, because it had that particular life). Ayers defends such an account:

Life is essential to the thing in so far as it is inconceivable that it (this thing) should have come into existence as a non-living thing. The thing exists, and

\footnotetext{
29 This strategy, in effect, turns an argument due to McGrath's (2005) on its head. McGrath argues that whatever puzzles common sense ontologists have about individually plausible but jointly inconsistent statements resurface for the eliminativist as statements that are individually plausibly correct but (still) jointly inconsistent.
} 
exists as it does, with the structure and parts that it has, because it is alive. In that sense we can say that life is its natural principle of existence and unity. But that is not to say that when it dies the thing itself will cease to exist: merely that an explanation of the existence and structure of the thing will then refer to a life that is over. The continued unity of a plant or animal after death obviously cannot be attributed to its continuing life, but even before death the conditions of its physical coherence at any one time were laid down by previous, rather than current, life-processes. (Ayers 1991, p. 184 my emphasis)

The historic-dependence account provides informative conditions of organisms' persistence: if an animal, A2 at $t_{2}$ is spatio-temporally continuous with and is the result of (or appropriately caused by) a life that is over, which belonged to $\mathrm{A} 1$ at $\mathrm{t}_{1}$, then $\mathrm{A} 1=\mathrm{A} 2$.

The historic-dependence account can also be used to justify a particular view on corpse parthood. Suppose vitalicists think that an artificial heart is not a proper part of the organism, because being inorganic it cannot participate in its organic life processes. There are various biochemical processes that proper parts of organisms can whereas inorganic objects cannot participate in. Nothing prevents somaticists from simply agreeing: they can argue that the artificial heart did not appropriately participate in any of the organic processes of the living animal and does not result from the organic processes of that life. Therefore, it is not a part of the dead organism. ${ }^{30}$

Of course, this is only one way of filling in the details. I am not deeply wedded to this view-I am merely trying to show that the somaticist can provide informative details about parthood and persistence. Is the historic-dependence account committed to the view that the corpse never acquires new parts that were not parts of the once living organism? As a corpse decomposes, many chemical reactions take place. Molecules enter as the organs liquefy; as microbes enter the dead organism, they produce substances like lactic acid and methane; gasses are produced as the body decomposes, etc. Here, the somaticist can adopt either of two accounts. On one account, if these new parts were not part of the life process of that animal immediately before it died, then they are not parts of the corpse. On another account, since decomposition itself is a natural process, whatever participates in this process has the potential to become a part of the corpse. I will not attempt to work out a detailed account along these lines. I only want to suggest that somaticists can, in fact, provide some detailed information regarding the conditions of being the part of a somatic organism after it dies.

However, there is a related worry. Even if somaticists can give us some details about what happens to the corpse after death, are these details principled? I will address this worry in the next section.

\footnotetext{
30 Indeed, this is exactly Ayers's view: “... what was initially a foreign body becomes a part of the individual by coming to participate in the common life, as in grafting or transplant surgery. A plastic hip-joint, however, like a false tooth, can never become part of the individual" (Ayers 1991, p. 185). Of course, the vitalicist might also claim that inorganic objects can be proper parts of an organism, if they adequately participate in the organism's life. And, again, the somaticist is free to agree. The point is that if the vitalicist has a good account of what counts as part of a living organism, nothing prevents the somaticist from adopting an analogous account appropriately modified in the shape of the historical-dependence view.
} 


\subsection{The unprincipledness objection}

Some vitalicists have complained that determining persistence conditions in terms of structure is very unprincipled. In the case of a living organism, different parts of the body form an "integrative unity": the organism possesses a property that is the result of the interaction of its parts, and that property is not reducible to any combination of properties of the parts (Shewmon 2001, p. 460). So the vitalicist has a principle that determines the persistence conditions of an organism (it persists so long as it is an integrative unity). However, the corpse's parts do not interact (or work together) in order to decompose it. Since an arm will decompose in more or less the same way whether it is attached to a corpse or detached from it, how can we determine whether or not it is a part of the corpse? The vitalicist appears to have a simple answer: roughly, organism $x=$ organism y iff they have the same life (see Van Inwagen 1990, p. 145; Olson 1997, p. 138 for such accounts). Appealing to structural features might seem unprincipled in comparison, since apart from the functioning of the organism, structure just comes down to whether or not the remains still look like the previous living organism, or judgments about whether enough of the flesh or the bones got preserved (Olson 2013).

The somaticist has two responses. First, it is false that structure comes down to judgments about similarity to the previous living organism; similarly to what Shewmon calls integrative unity, structure too is a property that does not reduce to those of the corpse's parts. Moreover, not only is an entire sub-discipline of biology, anatomy, devoted to the study of structure, but structural features of dead organisms are also frequently invoked in other areas. The case of $\mathrm{O}$. unilateralis and the infected ant is a case in point: some of the structural features of dead ants figure in the description of the life cycle of the $\mathrm{O}$. unilateralis. For example, the fungus always produces a large stalk that grows from the back of the dead ant's head (Pontoppidan et al. 2009, p. 2), and the fungus can grow such a stalk several times from the dead ant's body until the ant completely disappears (Mongkolsamrit et al. 2012, p. 218 my emphasis). There is nothing about structure that somehow makes it a less principled criterion of persistence than life.

Second, the somaticist can concede that while on her account a corpse persists as long as enough of the structure is preserved, there can be reasonable disagreement as to how much is enough. This doesn't point to any deep problem with the historic dependence view; it simply shows that adopting the view doesn't automatically settle every question about organism persistence. Take, for instance, a corpse whose hand gets cut off: do we have a scattered object or a non-scattered corpse that no longer has the hand as a proper part (Olson 2013)? If you place more weight on the qualitative similarity of parts you would say the hand is a part of the corpse. If more weight is placed on physical connectedness, you might want to deny this. I can think of reasons to go either way, but have no interest to settle the issue here.

Note that in this regard, there is nothing special about somaticism: vitalicists too face similar puzzle cases. Suppose Mort's brain surgery requires craniotomy, a procedure in which a part of the skull is temporarily removed to expose the brain. After the surgery, the surgeons put that part of the skull back in its place (often, they first insert 
it into the abdomen before putting it back in its place, or in refrigeration). ${ }^{31}$ Did Mort temporarily not have that piece of skull as a part? Did he have it, so that he was a scattered object for a while? In addition, one can also ask if dead skin cells are part of Mort, or hair tips and the tips of his fingernails. Are they caught up in the life of the organism?

Now of course, you may be a vitalicist, and you may have strong views about these cases ("of course I temporarily don't have a part of the skull during the surgery!"/"of course I temporarily exist as a scattered object!"). Note, however, that vitalicism by itself does not decide these questions. Whatever your preferred answers to these questions, they will be optional extra commitments over and above vitalicism. Moreover, this is not a cost of the view. Mutatis mutandis for the historic dependence account: it is compatible with the view that organisms can gain parts after their death, and also with the view that they can't. But this is not a flaw of the view; it just shows that the view has several defensible versions. I consider this flexibility a virtue rather than a vice.

One might still push the following line of thought. It seems that the most principled way of accounting for organism persistence is simply in terms of a continued life. This kind of an account — endorsed by the vitalicist—does not suffer from any disunity, which may seem unprincipled. However, as I explained before, the issue is not whether or not the expressions used to describe the persistence conditions of organisms are disjunctive or not, but how natural the properties are. I argued that being a somatic organism was more natural than being a vitalic organism. Of course, the historic dependence account uses disjunctive language to specify persistence conditions. But that is not a problem: the unity of the property is not necessarily reflected by the nondisjunctiveness of the predicates standing for it. Although I use disjunctive language to formulate the theory, this language does not refer to or quantify over less unified properties.

In the next section I will turn to what strikes me as the strongest objection to somaticism, by Olson (2013). According to this objection being an organism is a natural kind concept, and as such, things falling under it are unlikely to have disjunctive persistence conditions. However, if somaticism is correct, it seems unavoidable that organisms have disjunctive persistence conditions. Therefore, somaticism cannot be right.

\subsection{The disjunctiveness objection}

Above I proposed the historic-dependence account as an especially promising version of somaticism. If we attempt a more precise formulation of the account, the persistence conditions of organisms would be disjunctive. Olson, for instance, offers the following formulation:

\footnotetext{
31 For more information on craniotomy see Jandial et al. (2011). Other examples involving temporary removal of body parts include skin grafting involving an autograft, in which skin taken from a different location of the individual's body is transplanted in a different location, and nerve grafting, in which nerves from one part of an individual's body are transplanted into a different location.
} 
If $\mathrm{x}$ is an organism at $\mathrm{t}$ and $\mathrm{y}$ exists at a later time $\mathrm{t}^{*}, \mathrm{x}=\mathrm{y}$ if and only if either i. $y$ is alive at $t^{*}$ and the event that is y's life at $t^{*}=$ the event that is $x^{\prime}$ s life at $\mathrm{t}$, or ii. $\mathrm{y}$ is not alive at $\mathrm{t}^{*}, \mathrm{y}$ is composed at $\mathrm{t}^{*}$ of a sufficient proportion of the particles that compose $\mathrm{x}$ when $\mathrm{x}$ dies, $\mathrm{y}$ 's particles at $\mathrm{t}^{*}$ are arranged at every time between $x$ 's death and $t^{*}$ more or less as they are when $x$ dies, and at $t^{*} y$ is not a part of any other thing whose particles relate to x's in these ways. (Olson 2013, p. 91)

This formulation is consistent with Ayers' account given in the previous section, but is more precise. So a somaticist might as well adopt it.

Olson identifies the following problem with the disjunctive persistence conditions given above:

The disjunctiveness objection Disjunctive concepts do not carve at the joints but cover "disparate phenomena to suit our interests" (Olson 2013, p. 92). Organism, however, is a natural kind concept and as such cannot be irreducibly disjunctive. These considerations do not entail that the persistence conditions of organisms are not disjunctive, but "it would certainly be surprising if they were" (2013, p. 92). In other words, it is highly unlikely that a thing falling under a natural-kind concept, which is not disjunctive, will have disjunctive persistence conditions.

The argument can be divided into two main steps. The first step is intended to establish that organism cannot be irreducibly disjunctive:

(P1) If a concept carves at the joints, it cannot be irreducibly disjunctive (henceforth No Disjunctive Joints).

(P2) Natural kind concepts carve at the joints.

(P3) Therefore, natural kind concepts cannot be irreducibly disjunctive.

(P4) Organism is a natural kind concept.

(C1) Therefore, organism cannot be irreducibly disjunctive.

Olson has little to say about what he means by an irreducibly disjunctive concept. He might mean something like the following. ${ }^{32}$ Any property could be expressed by or referred to with a disjunctive predicate or captured by a disjunctive concept, so it is possible to construct a disjunctive concept for any property. For example, take the predicate 'grold or gral': 'grold' refers to the property of being green and discovered at least 300 years ago and 'gral' refers to the property of being green and not being discovered at least 300 years ago. Presumably, we can express this disjunction by simply using the predicate 'green'. So, 'grold or gral' is arguably not irreducibly disjunctive. ${ }^{33}$ In contrast, an irreducibly disjunctive concept expresses a property that cannot be perspicuously expressed by a non-disjunctive concept. For instance, the

\footnotetext{
32 Olson does not specify how he construes the relation between predicates, concepts and properties. I do not wish to assume any particular view about their relation here. All Olson needs to assume is that if the concept of an organism is disjunctive, or if the property is disjunctive, then the persistence conditions that apply to things falling under that concept, or instantiating the property, are likely to also have disjunctive persistence conditions. If this assumption is false, it's all the worse for Olson's argument.

33 I'm not assuming that necessarily coextensive predicates stand for the same property, but it's plausible that these two predicates do. If you disagree, you can replace it with an example according to your theoretical leanings.
} 
predicate 'grue' applies to all things that were examined before some time $t$ and are green, and to other things in case they are blue (Goodman, 73). While 'grue' is not a disjunctive expression, it has been introduced to stand for a concept that is most perspicuously expressed by a disjunctive predicate.

The second step in Olson's argument starts with the intermediary conclusion that organism cannot be irreducibly disjunctive and goes on to argue that the historicdependence account violates this requirement:

(P5) If the historic-dependence account is true, then organisms have disjunctive persistence conditions.

(P6) Organism cannot be irreducibly disjunctive (the conclusion from P1-P4 above).

(P7) If organism cannot be irreducibly disjunctive, then organisms don't have disjunctive persistence conditions.

(P8) Therefore, organisms don't have disjunctive persistence conditions.

(C2) Therefore, the historic dependence account is false.

Olson holds that P7 is highly likely to be true. Although he allows that some not irreducibly disjunctive concepts may have disjunctive persistence conditions, he thinks that organism is highly unlikely to be among them. Vitalicists don't face this problem, since on their view we can account for the persistence of organisms in terms of their lives.

For the sake of the argument, assume that the property of being an organism is the property of being a somatic organism, the historic-dependence account is true, and so organisms have irreducibly disjunctive persistence conditions. If we assume this much, then we can also suppose that organism is an irreducibly disjunctive concept. Does this mean that the property of being a somatic organism is not natural, or less natural than the property of being a vitalic organism? The previous considerations suggest that this is not the case.

First of all, notice that there is nothing in the notion of a disjunctive property that prevents it from being natural in the scientific sense. I cannot give a general account of exactly which disjunctive properties are natural, but I can give some plausible examples. As Clapp (2001) points out, determinable properties have a unified causal profile: there is a deep similarity between being this particular shade of red and that particular shade of red. The same goes for multiply realizable special science properties and their realizers. On a natural construal these properties are disjunctive; but they are not thereby gerrymandered.

In the earlier sections of this paper I gave ample reason to think that living and dead organisms are closer to different shades of red or different realizers of the same multiply realizable property than to arbitrarily disjoined properties, such as being a chair or being an electron. For example, as I noted in the zombie ant example, the exact moment of the ant's death doesn't mark any interesting turning point in the fungus's development; so, the causal powers of the dead and of the living ants are much more unified than those of totally miscellaneous things. Moreover, according to the most important criterion of naturalness on the scientific conception, the property of being a somatic organism is at least as natural as the property of being a vitalic organism. As we have seen, it is a core concept of biology that figures in a number of biological descriptions, generalizations, and (depending on our conception of lawhood) even 
laws, and it is better suited to play these roles than the property of being a vitalic organism is. So even if being a somatic organism is disjunctive, it is still a natural property. This result undermines the No Disjunctive Joints premise (P1), according to which if a concept carves at the joints, it cannot be irreducibly disjunctive. With this premise undermined, Olson's argument against somaticism turns out to be unsound. ${ }^{34}$

\section{Conclusion}

If the preceding considerations are correct, they show two things. First, the property of being a somatic organism-even if it imposes disjunctive persistence conditions on the things that have it - is natural, and arguably a better candidate to be meant by 'is an organism' than being a vitalic organism is. Second, somaticism can be informative regarding the persistence conditions of organisms, as well as the conditions for something being part of an organism; and to the extent that it is subject to puzzle cases, these are cases with close analogues that are equally problematic for vitalicism. These considerations strongly suggest that the somaticist conception of organisms is superior to its vitalicist rival. Judith is right, after all, to say that Romeo is presently a dead chimpanzee, whose corpse is lying before her.

Acknowledgements I would like to thank Berit Brogaard, Simon Evnine, Amy Kind, David Mark Kovacs, Mark Rowlands, Amie Thomasson, anonymous referees, and audiences at the "Animals and Death" conference at the University of Leeds and at the 2015 "Ontology and Metaontology" summer school at the Central European University for helpful feedback and comments on earlier versions of this paper. Special thanks to Rumya Sundaram for helpful discussions and insights about biology.

\section{References}

Andersen, S., et al. (2009). The life of a dead ant: The expression of an adaptive extended phenotype. The American Naturalist, 174(3), 424-433.

Andersen, S., \& Hughes, D. (2012). Host specificity of parasite manipulation Zombie ant death location in Thailand vs. Brazil. Communicative \& Integrative Biology, 5(2), 163-165.

Armstrong, D. M. (1978). Universals and scientific realism. Cambridge: Cambridge University Press.

Árnadóttir, S. T. (2015). Overdetermination and elimination. International Journal of Philosophical Studies, 23(4), 479-503.

Ayers, M. (1991). Locke: Epistemology \& ontology. London: Routledge.

Blatti, S. (2014). Animalism. In Stanford Encyclopedia of Philosophy. http://plato.stanford.edu/entries/ animalism/.

Beatty, J. (1995). The evolutionary contingency thesis. In G. Wolters \& J. Lennox (Eds.), Concepts, theories, and rationality in the biological sciences (pp. 45-81). Pittsburgh: University of Pittsburgh Press.

Carter, W. R. (1984). Death and bodily transfiguration. Mind, 93(371), 412-418.

\footnotetext{
34 Another virtue of the preceding defense of somaticism is that it bypasses the following, related problems. One reason to accept vitalicism is that there are various asymmetries between living organisms and corpses. For example, Hershenov (2009) suggests that whereas a living organism may assimilate various parts in a particular way, which may involve incorporating these parts into the organism's metabolic processes, a corpse cannot do so (see Hershenov 2009; Laporte 2009 for a discussion of the significance of these asymmetries). While some have tried to argue that we can brush away these asymmetries by appealing to some higher principle that both living organisms and corpses obey (Laporte 2009), we can bypass the need to specify such a principle by showing that these asymmetries do not undermine the naturalness of the property that the persistence conditions track.
} 
Carter, W. R. (1988). Our bodies, our selves. Australasian Journal of Philosophy, 66, 308-319.

Carter, W. R. (1989). How to change your mind. Canadian Journal of Philosophy, 19, 1-14.

Carter, W. R. (1999). Will I be a dead person? Philosophy and Phenomenological Research, 59, 167-172.

Clapp, L. J. (2001). Disjunctive properties: Multiple realizations. Journal of Philosophy, 98(3), 111-136.

De Bekker, C., et al. (2014). From behavior to mechanisms: An integrative approach to the manipulation by a parasitic fungus (Ophiocordyceps unilateralis s.1.) of its host ants (Camponotus spp.). Integrative and Comparative Biology, 54(2), 166-176.

Delaney, J., \& Hershenov, D. B. (2009). Why consent may not be needed for organ procurement. The American Journal of Bioethics, 9(8), 3-10.

Dorr, C., \& Hawthorne, J. (2013). Naturalness. In K. Bennett \& D. Zimmerman (Eds.), Oxford studies in metaphysics (Vol. 8, pp. 3-78). Oxford: Oxford UP.

Elgin, M. (2006). There may be strict empirical laws in biology, after all. Biology and Philosophy, 21, 119-134.

Evans, H. C., Elliot, S. L., \& Hughes, D. P. (2011). Ophiocordyceps unilateralis: A keystone species for unraveling ecosystem functioning and biodiversity of fungi in tropical forests? Communicative \& Integrative Biology, 4(5), 598-602.

Feldman, F. (1992). Confrontations with the reaper: A philosophical study of the nature and value of death. New York: Oxford UP.

Feldman, F. (2000). The termination thesis. Midwest Studies in Philosophy, 24, 98-115.

Forster, M., \& Sober, E. (1994). How to tell when simpler, more unified, or less ad hoc theories will provide more accurate predictions. The British Journal for the Philosophy of Science, 45, 1-35.

Hershenov, D. (2005). Do dead bodies pose a problem for biological approaches to personal identity? Mind, 114(453), 31-59.

Hershenov, D. (2009). Organisms and their bodies: Response to LaPorte. Mind, 118(471), 803-809.

Hershenov, D. B., \& Delaney, J. J. (2010). The metaphysical basis of a liberal organ procurement policy. Theoretical Medicine and Bioethics, 31, 303-315.

Hughes, D. P., et al. (2011). Behavioral mechanisms and morphological symptoms of zombie ants dying from fungal infection. BMC Ecology, 11(13), 1-10.

Jandial, R., et al. (2011). Core techniques in operative neurosurgery. Philadelphia: Elsevier/Saunders.

Kim, J. (1998). Mind in a physical world. Massachusetts: MIT Press.

Laporte, J. (2009). On two reasons for denying that bodies can outlast life. Mind, 118(471), 795-801.

Lewis, D. K. (1983). New work for a theory of universals. Australasian Journal of Philosophy, 61, 343-377.

Lewis, D. K. (1984). Putnam's paradox. Australasian Journal of Philosophy, 62(3), 221-236.

Liao, S. M. (2010). Twinning, inorganic replacement and the organism view. Ratio, 23(1), 59-72.

Mackie, D. (1999). Personal identity and dead people. Philosophical Studies, 95, 219-242.

McGgrath, M. (2005). No objects, no problem? Australasian Journal of Philosophy, 83(4), 457-486.

Merricks, T. (2001). Objects and persons. Oxford: Oxford UP.

Mitchell, S. D. (1997). Pragmatic laws. Philosophy of Science, 64, 468-479.

Mitchell, S. D. (2000). Dimensions of scientific laws. Philosophy of Science, 67, 242-265.

Mongkolsamrit, S., et al. (2012). Life cycle, host range and temporal variation of Ophiocordyceps unilateralis/Hirsutella formicarum on Formicine ants. Journal of Invertebrate Pathology, 111, 217-224.

Olson, E. (1997). The human animal: Personal identity without psychology. New York: Oxford UP.

Olson, E. (2003). An argument for animalism. In R. Martin \& J. Barresi (Eds.), Personal identity (pp. 318-334). Oxford: Blackwell.

Olson, E. (2004). Animalism and the corpse problem. Australasian Journal of Philosophy, 82(2), 265-274.

Olson, E. (2013). The person and the corpse. In B. Bradley, et al. (Eds.), The oxford handbook of philosophy of death (pp. 80-96). New York: Oxford UP.

Pepper, J. W., \& Herron, M. D. (2008). Does biology need an organism concept? Biological Reviews, 83, 621-627.

Pontoppidan, M.-B., et al. (2009). Graveyards on the move: The spatio-temporal distribution of dead Ophiocordyceps-infected ants. PLoS ONE, 4(3), 1-10.

Schaffer, J. (2004). Two conceptions of sparse properties. Pacific Philosophical Quarterly, 85, 92-102.

Shewmon, D. A. (2001). The brain and somatic integration: Insights into the standard biological rationale for equating 'brain death' with death. Journal of Medicine and Philosophy, 26(5), 457-478.

Sider, T. (1993). Naturalness, intrinsicality, and duplication. Ph.D. Thesis, University of Massachusetts/Amherst. 
Sider, T. (2003). What's so bad about overdetermination. Philosophy and Phenomenological Research, 67, $719-726$.

Sider, T. (2011). Writing the book of the world. New York: Oxford UP.

Smart, J. J. C. (1959). Can biology be an exact science? Synthese, 11(4), 359-368.

Snowdon, P. F. (1990). Persons, animals, and ourselves. In C. Gill (Ed.), The person and the human mind: Issues in ancient and modern philosophy (pp. 83-107). Oxford: Clarendon Press.

Snowdon, P. F. (1991). Personal identity and brain transplants. In D. Cockburn (Ed.), Human beings (pp. 109-126). Cambridge: Cambridge University Press.

Snowdon, P. F. (1995). Persons, animals, and bodies. In J. L. Bermúdez, A. Marcel, \& N. Eilan (Eds.), The body and the self (pp. 71-86). Cambridge MA: MIT Press.

Sober, E. (1997). Two outbreaks of lawlessness in recent philosophy of biology. Philosophy of Science, 64, $458-467$.

Sober, E. (2015). Ockham's razors: A user's manual. Cambridge: Cambridge UP.

Thomson, J. J. (1997). People and their bodies. In J. Dancy (Ed.), Reading parfit (pp. 202-229). Oxford: Blackwell.

Uzquiano, G. (2004). Plurals and simples. The Monist, 87(3), 429-451.

Van Inwagen, P. (1990). Material beings. Ithaca: Cornell UP.

Williams, J. R. G. (2007). Eligibility and inscrutability. Philosophical Review, 116(3), 361-399.

Yang, E. (2013). Eliminativism, interventionism and the overdetermination argument. Philosophical Studies, 164(2), 321-340. 